\title{
Malignant Mesothelioma of Peritoneum: About a Case with Review of the Literature
}

\author{
Berhil H*, Chenna H, Nouni K, Mouhajir N, Tolba A, Zaidi H, Mezouri V, Hassouni K, Kebdani T, El gueddari BK and Benjaafar N
}

Department of Radiotherapy, National Oncology Institute, Rabat, Morocco

\begin{abstract}
Malignant mesothelioma of the peritoneum is rather unusual and is only $10-20 \%$ of malignant mesothelioma. Malignant mesothelioma is pleural recognized by its location. The etiology of malignant mesothelioma is in $80 \%$ of cases prior contact with asbestos but there are cases without specific cause. The prognosis for MPM is poor with median survival of 5.4 months versus 12.5 months for pleural mesothelioma. The diagnosis of MPM is often difficult and requires surgical biopsies by laparoscopy or laparotomy or ascitic cytology. A surgical cytoreduction combined with hyperthermic intraperitoneal chemotherapy is the best therapeutic approach for MPM but unfortunately often advanced disease at diagnosis. We must therefore resort to systemic chemotherapy based on platinum or symptomatic treatments.
\end{abstract}

Keywords: Mesothelioma; Asbestos; Chemotherapy; Surgery

\section{Introduction}

Malignant mesothelioma of the peritoneum are rare primary tumors (1 case per million population per year). They are difficult to approach clinical, radiological, histological and therapeutic, keeping a poor prognosis.

\section{Case Report}

We report a patient aged 29 with no history notables. The disease onset was in two months made by symptoms of epigastric pain, constipation and abdominal bloating. Clinical examination found a distended abdomen with dullness in the blanks. An ultrasound was done has objectified the presence of ascites associated with peritoneal granulations. Laparoscopy showed a massive infiltration of the peritoneal cavity of granules with retraction of the omentum. Pathological examination revealed a dedifferentiated tumor infiltration of the omentum in favor of a multifocal malignant mesothelioma. A thoracoabdominal CT scan done showed the presence of a peritoneal effusion of abundance without visible organized mass. The patient received chemotherapy with an improvement in clinical symptoms and then forgotten.

\section{Discussion}

Peritoneal mesothelioma is a rare condition characterized by diffuse invasion of peritoneal surfaces. The incidence of pleural and peritoneal mesothelioma has universally increased since 1970. In industrialized countries, its incidence is currently estimated 0.5 to 3 cases per million inhabitants in men and 0.2 to 2 cases per million in women [1]. Peritoneal mesothelioma accounts for $1 / 5$ to $1 / 4$ of all clinical forms of mesothelioma [2]. The average age of onset is 50 years (17-76 years) and this disease affects the same frequency with the two sexes [3]. Prolonged exposure to asbestos is often implicated as a factor responsible for the development of the disease especially in pleural [4]. The relationship between peritoneal mesothelioma and asbestos exposure is unclear, especially among women, nor established as it is in the pleural mesothelioma $[1,5]$. Other agents have been reported such as exposure to erionite, viral infections and vaccine products and / or genetic susceptibility. Simian virus- 40 has been implicated and may be a co-carcinogen [6]. Other possible etiologies such as abdominal radiotherapy [7], chronic peritonitis [8], exposure to mica [9], the administration of thorium dioxide [10], were discussed. The mean interval between initial exposure and death is 48.7 years (range 14 to 72 years). The significance of the discrepancy is explained by the extent of exposure to asbestos and the type of fiber and the clinical picture is not spécific. However, three main signs are generally encountered:Abdominal pain: they are polymorphic which can simulate the entire digestive pathology. They have as their common characteristic tenacity. Ascites found in $90 \%$, it is often late, abundant, recurrent, persistent, usually serofibrinous, rarely gelatinous. The transit disorders fickle, they are made of alternating diarrhea - constipation, sometimes up to simulate an occlusive crisis. Palpation of an abdominal mass is common and association with pleural involvement is common. The alteration of general condition with anorexia and weight loss is a later onset during evolution. Forms simulating ovarian cancer, a liver tumor or tables of peritonitis have been reported [11-13]. The diagnosis of MPM is often difficult and laborious because the abdominal CT scan can detect leaks or peritoneal nodules. The magnetic resonance imaging, with its power characterization and tissue studies and multi-sequential and multiplanar, certain is of interest both for the diagnosis of extension for the differential diagnosis. It may indeed make a tissue in the direction of fibrous homogeneous low signal on $\mathrm{T} 1$ or T2-enhancing low $\mathrm{T} 1$ gadolinium [14]. PET-CT can be useful because it provides images with higher resolutions, but these tests can detect nothing [15]. Diagnosis is based on the histology of the peritoneal biopsies done by laparoscopy or laparotomy [16] and sometimes puncture cytology of ascites also allows for the diagnosis. Markers of malignant mesothelioma in immunohistochemistry are Cytokeratin 5 and 6 and calretinin. The intervention radiologists or coelioscopistes in the invasive diagnosis must be cautious. This tumor is of a very important ability to spread at the puncture routes, ports or trocars in laparoscopic abdominal

*Corresponding author: Berhil H, Department of Radiotherapy, National Oncology Institute, Rabat, Morocco, E-mail: berhilhanane@yahoo.fr

Received June 25, 2012; Accepted July 27, 2012; Published July 30, 2012

Citation: Berhil H, Chenna H, Nouni K, Mouhajir N, Tolba A, et al. (2012) Malignant Mesothelioma of Peritoneum: About a Case with Review of the Literature. J Cancer Sci Ther 4: 235-236. doi:10.4172/1948-5956.1000147

Copyright: ( 2012 Berhil $\mathrm{H}$, et al. This is an open-access article distributed under the terms of the Creative Commons Attribution License, which permits unrestricted use, distribution, and reproduction in any medium, provided the original author and source are credited. 
incisions. Whatever the invasive method used, it must pass through the midline. The introduction of lateral trocars for laparoscopy should be avoided because it often leads to parietal dissemination of the disease. Pathologists in the Washington Cancer Institute have identified seven different histological types of peritoneal mesothelioma among 68 patients [3] multicystique mesothelioma, mesothelioma low grade, the papillary well-differentiated, the epithelium, the biphasic, and sarcomatous the déciduoïde [3,17]. The genetic study of malignant mesothelioma often brings the same type of discrepancy that is deletion of chromosome regions $1 \mathrm{p}, 3 \mathrm{p}, 9 \mathrm{p}, 6 \mathrm{q}$ and loss of chromosome 22. Electron microscopy remains the "gold standard" for diagnosis and should be used for difficult cases $[14,18]$. Treatment is primarily surgical. In recent years, the idea of surgical cytoreduction followed by Hyperthermic Intraperitoneal Chemotherapy (HIPEC) with cisplatin and sometimes more with 5-fluoroblastine or paclitaxel was very extensive. The result with this combination treatment is encouraging. Survival at 2 years and 3 years is respectively $77 \%$ and $64 \%$. The median survival is 67 months and progression-free survival is 17 months.

This attitude is to offer patients in good general condition and with localized disease. The favorable prognostic factors are rather young age "under 60", women and the absence of residual tumor after surgery $[15,16]$. Systemic chemotherapy is to provide for more advanced cases and inoperable, thus considered palliative. A combination of cisplatin with pemetrexed provides objective response rate of $26 \%$ and stable disease in $45.2 \%$ of patients. The median survival was 13.1 months against 8.7 months with pemetrexed alone. In the same study, the 1 -year survival was $66 \%$ in the association against $0 \%$ with pemetrexed alone [19]. Other associations with paclitaxel, doxorubicin and cyclophosphamide are reported [16,18]. Among the new molecules, note that bevacizumab (VEGF inhibitor) with gemcitabine and cisplatin seems to bring a better result [15]. The use of total abdominal radio therapy is rare. It is indicated in palliative situations and used as analgesic. The prognosis for MPM is poor and most often, the patient dies before having received treatment. Several prognostic factors have been identified. The main ones are represented by the radicality of cytoreductive surgery (i.e., by the volume and distribution of the residual tumor disease after surgery), the initial extension (assessed by the classification or Gilly Peritoneal Cancer Index Sugarbaker [20]) sex (better prognosis in women), histological type (types of epithelial and papillary types better prognosis than sarcomatous, and biphasic déciduoïde) and lymph node [21]. Other prognostic factors have been recently identified as the size of the cell nucleus or the number of mitoses [22]. For monitoring, a consensus was reached during the International Workshop on Peritoneal Surface Malignancies in 2006 in Milan: it must be by thoraco-abdominal and pelvic CT every 3 to 4 months the first 2 years then every 6 months. The realization of a CA125 assay has also been proposed when he was elevated preoperatively [23].

\section{Conclusion}

The rarity of peritoneal malignant mesothelioma and its atypical clinical presentations are often, this disease is diagnosed late in advanced stages. The standard imaging is not explaining the definitive diagnosis obtained on peritoneal biopsies. For the treatment of indolent disease is surgery with hyperthermic intraperitoneal chemotherapy.

\section{References}

1. Boffetta P (2006) Epidemiology of peritoneal mesothelioma: a review. Ann Oncol 18: 985-990.

2. Sugarbaker PH, Yan TD, Stuart OA, Yoo D (2006) Comprehensive management of diffuse malignant peritoneal mesothelioma. Eur J Surg Oncol 32: 686-691.
3. Sugarbaker PH, Welch LS, Mohamed F, Glehen O (2003) A review of peritonea mesothelioma at the Washington Cancer Institute. Surg Oncol Clin N Am 12: 605-621.

4. Wagner JC, Sleggs CA, Marchand P (1960) Diffuse pleural mesothelioma and asbestos exposure in the North Western Cape Province. Br J Ind Med 17: 260 271.

5. Welch LS, Acherman YI, Haile E, Sokas RK, Sugarbaker PH (2005) Asbestos and peritoneal mesothelioma among college-educated men. Int $\mathrm{J}$ Occup Environ Health 11: 254-258.

6. Bocchetta M, Di Resta I, Powers A, Fresco R, Tosolini A, et al. (2000) Human mesothelial cells are unusually susceptible to simian virus 40-mediated transformation and asbestos cocarcinogenicity. Proc Natl Acad Sci U S A 97: 10214-10219.

7. Gilks B, Hegedus C, Freeman H, Fratkin L, Churg A (1988) Malignant peritoneal mesothelioma after remote abdominal radiation. Cancer 61: 2019-2021.

8. Peterson JT Jr, Greenberg SD, Buffler PA (1984) Non-asbestos-related malignant mesothelioma. A review. Cancer 54: 951-960.

9. Chahinian AP, Pajak TF, Holland JF, Norton L, Ambinder RM, et al. (1982) Diffuse malignant mesothelioma. Prospective evaluation of 69 patients. Ann Intern Med 96: 746-755.

10. Maurer R, Egloff B (1975) Malignant peritoneal mesothelioma after cholangiography with thorotrast. Cancer 36: 1381-1385.

11. Fayemendy L, Tulliez M, Uzzan E, Abelanet R, Chaussade S, et al. (1996) Peritoneal mesothelioma revealed by episodes of reccurent spontaneous peritonitis. Gastroenterol Clin Biol 20: 99-102.

12. Matsukuma S, Aida S, Hata Y, Sugira Y, Tamai S (1996) Localized malignan peritoneal mesothelioma containing rhabdoid cells. Pathol Int 46: 389-391.

13. Wang YL, Yuan CC, Ng-HT (1997) Primary malignant peritoneal mesothelioma: a report of two cases. Zhonghua Yi Xue Za Zhi (Taipei) 59: 55-58.

14. Manavoglu O, Orhan B, Evrensel T, Ozcelik T, Yolcu I, et al. (1996) Malignant peritoneal mesothelioma following asbestos exposure. J Environ Pathol Toxicol Oncol 15: 191-194

15. Hassan R, Alexander R, Antman K, Boffetta P, Churg A, et al. (2006) Current treatment options and biology of peritoneal mesothelioma: meeting summary of the first NIH peritoneal mesothelioma conference. Ann Oncol 17: 1615-1619.

16. Feldman AL, Libutti SK, Pingpank JF, Bartlett DL, Beresnev TH, et al. (2003) Analysis of factors associated with outcome in patients with malignant peritoneal mesothelioma undergoing surgical debulking and intraperitoneal chemotherapy. J Clin Oncol 21: 4560-4567.

17. Sebbag G, Yan H, Shmookler BM, Chang D, Sugarbaker PH (2000) Results of treatment of 33 patients with peritoneal mesothelioma. Br J Surg 87: 1587 1593.

18. Pistolesi M, Rusthoven J (2004) Malignant pleural mesothelioma: update current management and newer therapeutic strategies. Chest 126: 1318-1329.

19. Jänne PA, Wozniak AJ, Belani CP, Keohan ML, Ross HJ, et al. (2005) Open-label study of pemetrexed alone or in combination with cisplatin for the treatment of patients with peritoneal mesothelioma: outcomes of an expanded access program. Clin Lung Cancer 7: 40-46.

20. Glehen O, Mohamed F, Gilly FN (2004) Peritoneal carcinomatosis from digestive tract cancer: new management by cytoreductive surgery and intraperitoneal chemohyperthermia. Lancet Oncol 5: 219-228.

21. Yan TD, Yoo D, Sugarbaker PH (2006) Significance of lymph node metastasis in patients with diffuse malignant peritoneal mesothelioma. Eur J Surg Oncol 32: 948-953.

22. Deraco M, Nonaka D, Baratti D, Casali P, Rosai J, et al. (2006) Prognostic analysis of clinicopathologic factors in 49 patients with diffuse malignant peritoneal mesothelioma treated with cytoreductive surgery and intraperitoneal hyperthermic perfusion. Ann Surg Oncol 13: 229-237.

23. Baratti D, Kusamura S, Martinetti A, Seregni E, Oliva DG, et al. (2007) Circulating CA125 in patients with peritoneal mesothelioma treated with cytoreductive surgery and intraperitoneal hyperthermic perfusion. Ann Surg Oncol 14: 500-508. 